\title{
Forecasting Corporate Bankruptcy Based on Managerial Overconfidence Using the Adaptive Neuro-Fuzzy Inference System
}

\author{
Yulius Eka Agung Seputra* \\ Accounting Laboratory, Vocational Education Program, Universitas Indonesia \\ *E-mail: yulius.eka@gmail.com
}

\begin{abstract}
This purpose of this study is to examine the relationship between managerial overconfidence and the prediction of bankruptcy and likelihood of the auditor's hesitation of the company's going concern over the financially distressed companies listed on the Indonesian Stock Exchange during 2014-2016. Managerial overconfidence is defined as the manager's excessive confidence that can be measured when the growth of the company's assets is higher than its sales growth. The financial condition is measured by the prediction of bankruptcy using the adaptive neuro-fuzzy inference system (ANFIS) model. The results showed that the likelihood of an auditor's hesitation of the company's going concerns is positively associated with managerial overconfidence in Indonesia because the auditor has a positive view on the ability of management. In addition, there is the likelihood that the auditor's hesitation of a company's going concerns is positively associated with the prediction of bankruptcy.
\end{abstract}

Keywords: auditor, managerial overconfidence, forecasting, corporate, bankruptcy, going concern, adaptive neuro-fuzzy inference system, ANFIS

\section{Introduction}

For stakeholders, financial reports are the most important reflection of a company's actual general circumstances (Măciucă, Hlaciuc, \& Ursache, 2015). Each company's financial statements are audited by a public accountant (auditor) to obtain an audit opinion on the correctness of the presentation of financial statements. An audit opinion is a certification of public confidence in the credibility and reliability of the financial statement (Kalelkar, 2016).

When there is doubt about the ability of the entity to survive in the coming year, the auditor issues what is called an audit opinion with going concern (George-Silviu \& MelindaTimea, 2015).

The auditor can make two errors with regard to an audit opinion with going concern. First, not providing a going concern opinion to the audit report on a company that went bankrupt. Second, providing a going concern opinion on a company that did not go bankrupt the following year (Lin \& Yeh, 2014). Uncertain economic conditions make it difficult to avoid either of these errors. The purpose of this study is to predict corporate bankruptcy by using the adaptive neuro-fuzzy inference system (ANFIS) as the basis for the going concern audit opinion.

\section{Literature Review}

\subsection{Agency Theory}

The agency problem occurs because of the different objectives of the company owner (principal) and the company's management (agent). A conflict of interest exists between the principal and agent. The principal is a provider of capital for the company. Meanwhile, the agent is the management in charge of running the company. Both want to maximize their 
respective interests, so there is no guarantee that the agent will always act in accordance with the interests of the principal (Tatiana, Prozan, \& Diana, 2015).

In the context of such relationships, owners and managers are assumed to be rational economic actors and to act solely on the basis of self-motivation. Therefore, there is often a conflict of interest between them. This conflict of interest occurs because of asymmetric information between the owner and the manager. For example, the manager could do something for his or her personal interests and ignore the interests of the owner (moral hazard) (Sedmihradská, 2015).

There are two kinds of information asymmetry: moral hazard and adverse selection. Moral hazard is an action performed by an agent that is inconsistent with the principal's interests. This is due to the tendency of negligent managers resulting in lower profitability than they should be able to generate. Meanwhile, adverse selection is a situation where parties from within the company take advantage by selling inside information that can lead to errors in decision-making. Two things cause adverse selection: insider trading and a manager concealing negative information about the company's future for the fear of affecting it. Principals can do several things to overcome this agency problem. Costs incurred to overcome agency problems are called agency costs. The principal's perception of how big an agency problem is determines the amount of agency costs incurred (Packham, 2018).

Agency costs consist of:

1. Monitoring expenditure (cost of supervision), which is the cost borne by the principal to monitor agent's behavior such as costs incurred to build an audit system and limit management's abuse.

2. Bonding expenditure (cost of agreement), which is the cost borne by the agent with principal burden (i.e., decreased profit) to establish and adhere to mechanisms that ensure that the agent will act in the interest of the principal.

3. Opportunity cost is the cost incurred by the company to have the opportunity to make a profit.

4. Structuring expenditures (cost structures) are costs incurred as a result of the company's structured compensation to provide incentives for managers to make their best efforts to maximize the principal's profits.

The auditor's role is to bridge the conflict of interest between the agent and principal. Principals require the auditor to verify the information that management provides to the company, whereas agents need auditors to provide legitimacy for their performance (in the form of financial statements) in order to receive incentives (Ittonen, Tronnes, \& Wong, 2017).

According to the principal, should be able to reduce the agency costs incurred to increase the company's value by disclosing company information and using good corporate governance as companies that have low transparency levels bear a large agency cost (Rodriguez-Fernandez, 2016)

\subsection{Managerial Overconfidence}

The key role of managers is to forecast the company's future in terms of demand, cash flow, and competition and use these predictions as input to design corporate policies (Jha \& Cox, 2015)

Overconfidence is described as a behavioral or psychological bias that causes estimates of future outcomes of current events to be too high. This exaggerated belief is primarily formed by a "better-than-average effect" (Adam, Fernando, \& Golubeva, 2015). Humans tend to regard themselves as above average; hence, estimates by overconfident management can lead 
to over-optimism, which may adversely affect corporate policy or corporate financial reporting decisions (Hill, Lopez, \& Reitenga, 2016).

Overconfident managers are viewed as managers who systematically overestimate the future profit forecasts of a company or systematically assess too many possibilities and the impact of beneficial events on the company's cash flow. They may also underestimate the likelihood of negative outcomes and the impact of events on the company's cash flow (Adam et al., 2015).

Overconfident management resulting in higher sensitivity between investment and free cash flow leads to excessive investment and low investment efficiency, but has a positive correlation with the decision on acquisition. These companies tend to merge, acquire, and pay more for the acquisition (Lai, Lin, \& Chen, 2017). Moreover, overconfident management prefers lower dividend payouts, tends to engage in inappropriate financial reporting to beat or meet their overly optimistic earnings expectations, is more likely to delay the recognition of losses, and is inclined to represent previously issued financial statements (Chung, Hrazdil, \& Trottier, 2015). Overall, the results of the study show that overconfident management influences corporate financial reporting behavior, reduces the quality of financial reporting, generates more earnings management, reduces the use of conservative accounting, and more frequently reports on restatements of financial statements.

\subsection{Financial Distress}

The financial condition of a company is the complete state of its finances over a period of time. Financial distress can be defined as a condition in which a company experiences difficult financial situations and is threatened with bankruptcy. Most previous studies have used case studies on companies that were legally declared bankrupt as a variable response to financial distress (Lian, 2017).

Management is often confronted with failure to raise the company. As a result, the company's going concern in the future is unclear. Businesses can become unhealthy or sick, and may even sustain through a prolonged crisis. This condition may lead to insolvency, bankruptcy, and liquidation. Bankruptcy is defined as the management's failure in running the company's operations to generate profits. Auditors rarely issue a going concern audit opinion to a company that does not face this difficulty (Foster \& Shastri, 2016), whereas they are more likely to issue it when it is possible that a bankruptcy will occur. The worse the financial condition of the company, the greater the probability of the company receiving a going concern opinion (Adams \& Glück, 2015).

According to Lian (2017), financial distress occurs for the following reasons:

1. Business failure-where a company goes bankrupt so that its business must be stopped and cause the creditors to bear the losses.

2. Legal bankruptcy — when a company submits a bankruptcy request to a court so that it can be officially declared bankrupt in accordance with the applicable law.

3. Technical insolvency - if a company cannot meet current liabilities when they mature.

4. Accounting insolvency - if the total book value of the company exceeds the value of its assets.

\subsection{Bankruptcy Prediction}

The bankruptcy prediction model is a tool for auditors to use to decide the company's ability to survive. This model affects the accuracy of the audit opinion as well as the acceptance of going concern audit opinion. The model can use genetic algorithm and fuzzy 
clustering as it is designed to be applicable in all sectors. (Chou, Hsieh, \& Qiu, 2017). Figure 1 illustrates how bankruptcy prediction uses the ANFIS model.

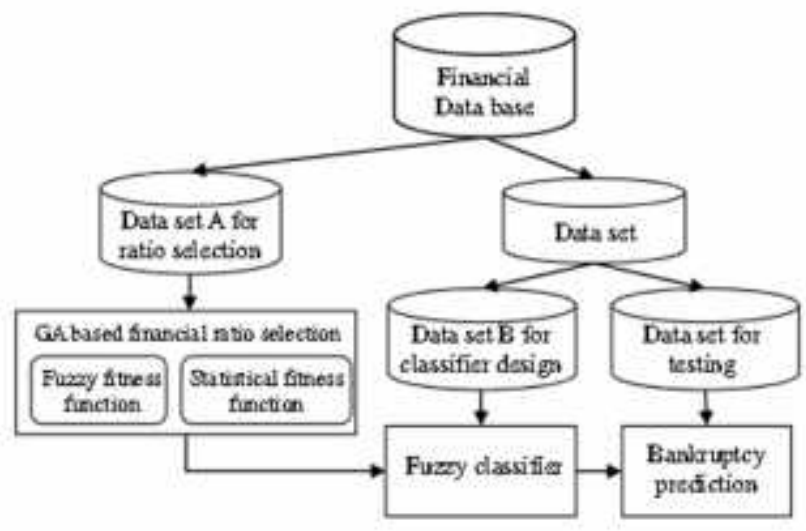

Fig. 1. ANFIS Data Set

\subsection{ANFIS}

ANFIS is a network structure in which the overall input-output behavior is determined by a set of modified parameters. One of the neural network structures is the multilayer perceptron (MLP) that specializes in advanced feed network. MLP is applied by training it using the back-propagation algorithm from error back-propagation (EBP). The ANFIS model is usually trained with the data sets of features from certain classes of chart patterns in financial time series (Wan \& Si, 2017).

ANFIS combines fuzzy logic and neural networks; it uses a hybrid learning algorithm that combines the methods of least squares estimator (LSE) and EBP. The model uses the membership function and works the entire network with fuzzy numbers. Figure 2 illustrates how the membership function works.

Company's financial condition and managerial overconfidence are the two inputs of the proposed ANFIS model while corporate bankruptcy is the sole output. The ANFIS model is able to determine how each of these factors affects the index in a quantitative way (Figure 3 ). 


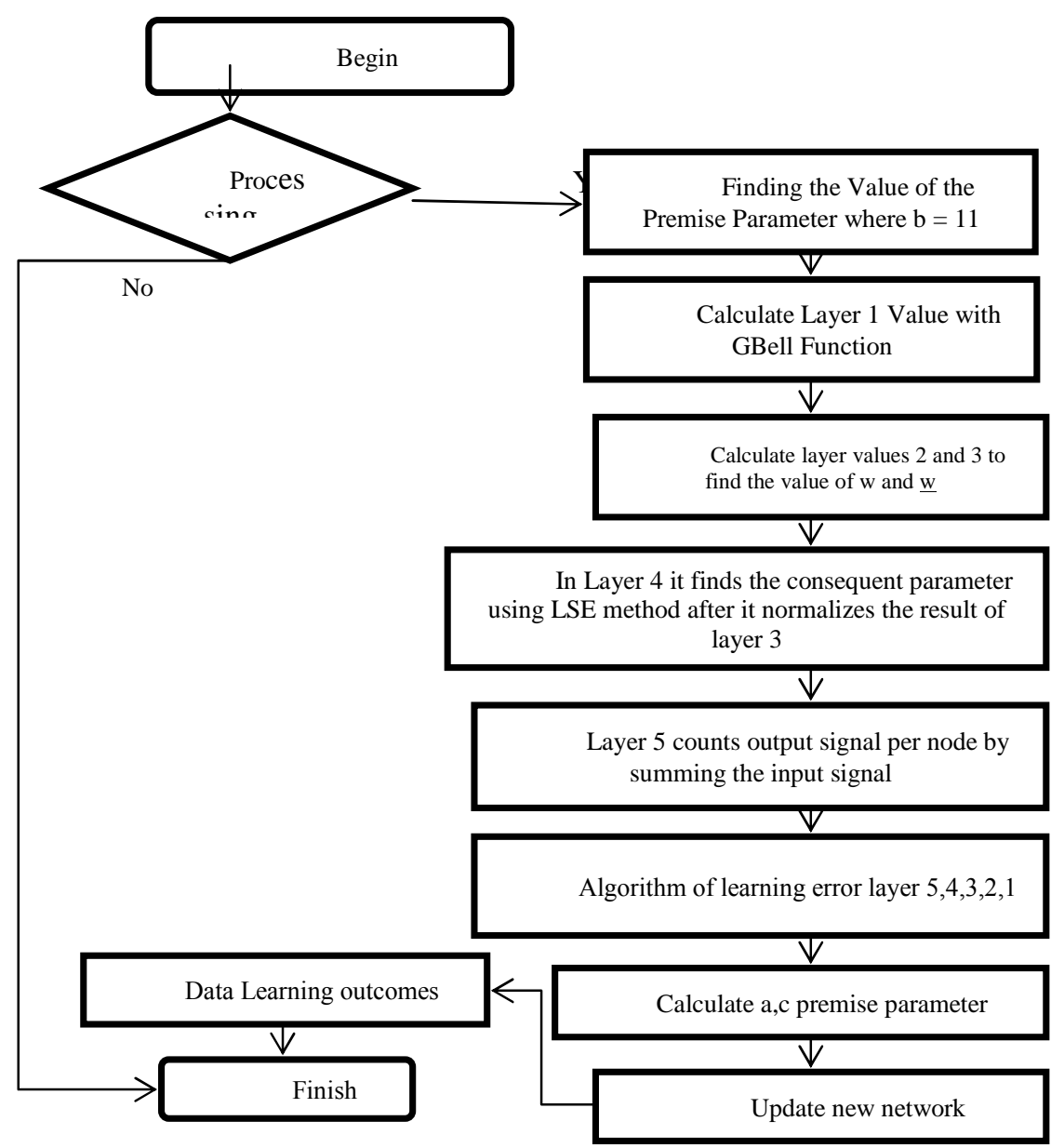

Fig. 2. ANFIS Flow Chart

The ANFIS process consists of several layers. The first layer of the input data in each period will be the fuzzyfication process. This process is to map the input data into the fuzzy set as per the selected classification (this study uses only two types of fuzzy sets, i.e., high and low).

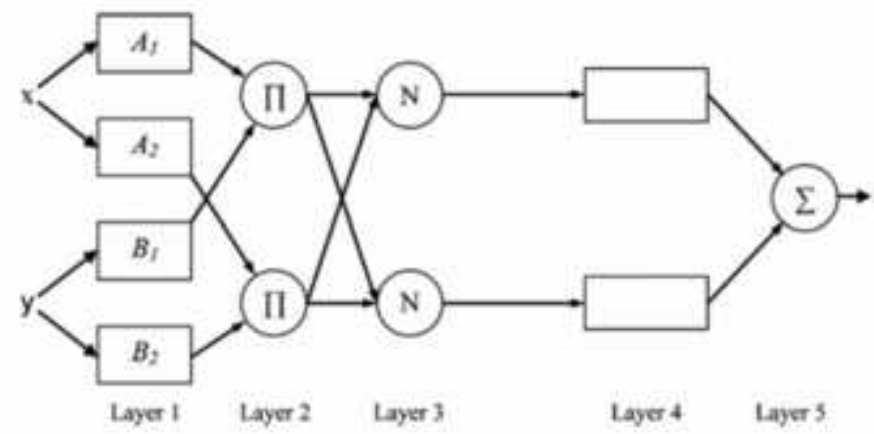

Fig. 3. ANFIS Block Diagram

In this process, input will be a calculated fuzzy membership function to transform the classical set of input (crisp data) to a certain degree. The membership function used is bellshaped that has two parameters, namely mean and variance, called the premise parameters. In 
the second and third layers, the inference engine process (fuzzy inference system) specified fuzzy rule for further calculation process. In this process, there is no calculation because the ANFIS system used has one input. The output node of this layer is the same as the output layer of node 1. Layer 3 is normalized as each vertex displays the degree of activation normalized. In Layer 4, the defuzzyfication process performs the calculation of transforming the fuzzy results into the crisp output form. In this layer, the LSE calculation is performed to obtain consequent parameter values. In Layer 5, a summary process of two outputs is executed on Layer 4. In ANFIS, the fuzzy system is located on Layers 1, 2, 3, and 4, where the fuzzy system is the hidden node determinant of the neural network system. The layers are explained as follows:

Layer 1: Each node $i$ in this layer is an adaptive node with a node function: n1a $=$ Bell $(x ; \mathrm{a} 1, \mathrm{~b} 1, \mathrm{c} 1)$ and $\mathrm{n} 2 \mathrm{a}=\operatorname{Bell}(x ; \mathrm{a} 2, \mathrm{~b} 2, \mathrm{c} 2)$, where $x$ is the input for vertices $\mathrm{n} 1 \mathrm{a}$ and $\mathrm{n} 2 \mathrm{a}$, whereas a1, b1, c1, a2, b2, c2 are the membership-level parameters of the fuzzy set A (=a1, a2, b1, OR b2), and determines the membership degree of the given $x$ input. The membership function parameters of A can be approximated by the bell function:

$$
\mu_{A}(x) \frac{1}{1+\left[\left(\frac{x-c}{z a}\right)^{2}\right]^{D}}
$$

where $\{a i, b i, c i\}$ is the set of parameters. The parameters in this layer are called premise parameters.

Layer 2: Each node in this layer is labeled n3a and n4a, non-adaptive (fixed parameters) that forward the results from Layer 1 . Because the system uses one input, there is no AND inference. Thus, the output on the second layer is: $\mathrm{n} 3 \mathrm{a}=\mathrm{n} 1 \mathrm{a}$

$$
\mathrm{n} 4 \mathrm{a}=\mathrm{n} 2 \mathrm{a}
$$

Layer 3: Each node in this layer is labeled n5a and n6a, also non-adaptive. Each vertex displays the degree of activation normalized to the shape. $n 5 a=n 3 a /(n 3 a+n 4 a) n 6 a=$ $\mathrm{n} 4 \mathrm{a} /(\mathrm{n} 3 \mathrm{a}+\mathrm{n} 4 \mathrm{a})$

\section{Layer 4:}

$$
A=\left[\begin{array}{llll}
(n 5 u) x(n) & n 5 u & (n 6 u) x(n) & n 6 u \\
(n 5 u) x(n) & n 5 u & (n 6 u) x(n) & n 6 u
\end{array}\right]
$$

Each node in this layer is an adaptive node, and we get the matrix A as follows: Number of matrix rows Asebanyak amount of input data $x$. In this layer, the consequent parameter values $\varnothing$ are sought with the LSE method. The equation of the method is as follows:

$$
\begin{aligned}
& \theta=i r \quad\left(A^{T} A\right) A^{T} \cdot y \\
& \text { With y=desired target output } \\
& \theta=\left[\begin{array}{llll}
p 1 & q 1 & p 2 & q 2
\end{array}\right]
\end{aligned}
$$

Furthermore, to calculate the output in the fourth layer, the following equation is used:

$$
\begin{aligned}
& \mathrm{n} 7 \mathrm{a}=\mathrm{p} 1 * \mathrm{x}+\mathrm{q} 1 \\
& \mathrm{n} 8 \mathrm{a}=\mathrm{p} 2 * \mathrm{x}+\mathrm{q} 2
\end{aligned}
$$

\section{Layer 5:}

Single nodes in this layer are labeled n9a, which calculates all outputs as the sum of all incoming signals:

$$
\begin{aligned}
& \mathrm{n} 9 \mathrm{a}=\mathrm{n} 7 \mathrm{a}+\mathrm{n} 8 \mathrm{a} \\
& \mathrm{Ts}(1, \mathrm{t})=\operatorname{Tg}(1, \mathrm{t})
\end{aligned}
$$

\section{Method}




\subsection{Experimental dataset}

The data collected included 396 samples; 101 samples of which were used for training and testing.

\subsection{Statistical Analysis}

In this study, four statistical criteria were utilized for measuring the predictive performance of the models. These criteria were the coefficient of determination (R2), root mean squared error (RMSE), standard deviation of error (STD), and mean absolute percentage error (MAPE).

\subsection{Desirability Function}

The purpose of the desirability function procedure is to convert multi-response problems into one-response problems by using transformation methodology. These multiple responses may be close to each other or may not have a uniform trend. Hence, individual and overall desirability functions were defined. The value of the desirability function ranges between 0 and 1 .

\subsection{ANFIS Modeling and Validation}

ANFIS is a hybrid neuro-fuzzy technique for the automatic tuning of a fuzzy-type inference system based on training data. The technique benefits from the advantages of both fuzzy logic and neural networks. This modeling approach perfectly fits the process with nonlinear behavior. After calculating the input parameters, the data were divided into two sections: training (78\%) and test (22\%). The ANFIS models were simulated by running the PREDIKTOR software package. For constructing ANFIS models, the PREDIKTOR application has been developed using C Sharp (C\#) Language.

\section{Discussion}

\subsection{Benefits}

The most obvious benefit of the use of ANFIS is the fact that this method opens many possibilities to extend the existing estimator into the mixed data setting. This is extremely useful with the increasing complexity of the estimators. In many cases, there is no straightforward way to adapt an estimator to mixed data.

A less obvious benefit arises for studying general properties of a nonparametric function estimation problem. In the continuous setting, asymptotic arguments are often easier and well established. For example, ANFIS arguments make it straightforward to derive minimaxoptimal rates of convergence in nonparametric mixed data models.

\subsection{Issues and Open Questions}

A key issue for nonparametric analysis depends on the estimators' characteristics. The main criterion is how "locally" the estimator operates; or more specifically, if the estimator is only affected by data in a compact neighborhood.

This methodology is only valid for nonparametric estimators, usually in the form of functionals.

\section{Results}

This work was partially supported by the Vocational Program, Universitas Indonesia. The author thanks the two anonymous referees for raising several interesting points that greatly improved the comprehensiveness of this contribution. 


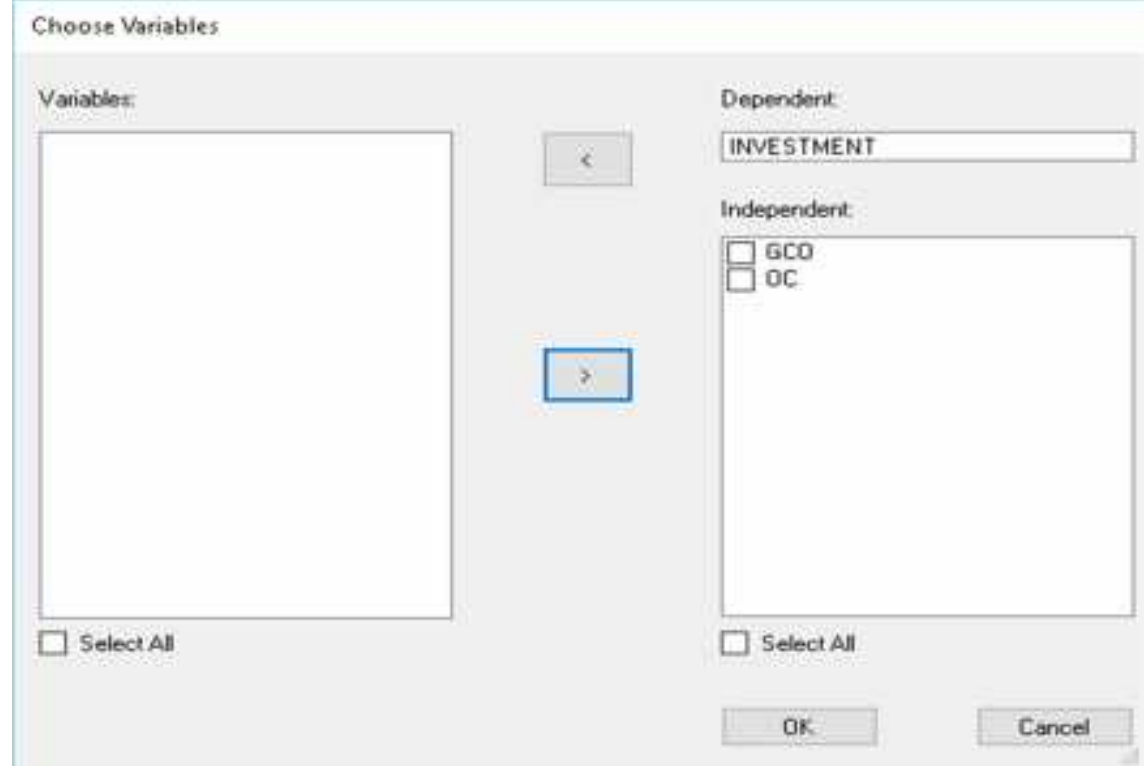

Fig. 4. ANFIS Independent and Dependent Variables

Figure 4 shows the independent variables used in ANFIS. The advantage of ANFIS is that it can handle free variables with different types.

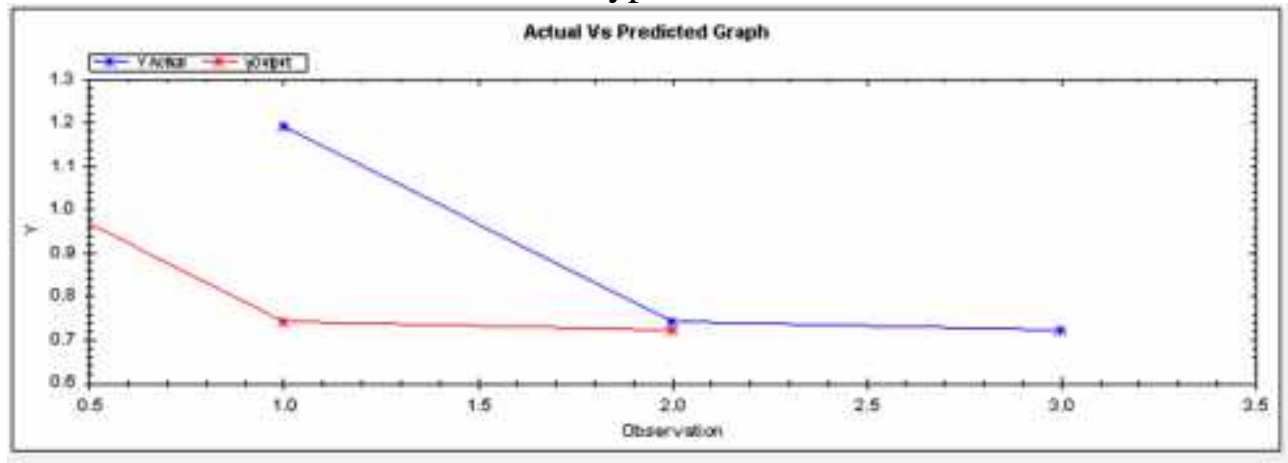

Fig. 5. ANFIS Learning Program

Figure 5 shows the process of learning variables using ANFIS. The model has the advantage that it can be used to recognize relationships between variables of different types.

Table 1. Variable Description

\begin{tabular}{ll}
\hline Variable & Description \\
\hline $\begin{array}{l}\text { Manager Overconfidence } \\
(\mathrm{OC})\end{array}$ & $\begin{array}{l}1 \text { if the company gets an opinion regarding the doubt on going concern, and } 0 \\
\text { otherwise. }\end{array}$ \\
$\begin{array}{l}\text { Audit Going Concern } \\
(\mathrm{GCO})\end{array}$ & $\begin{array}{l}1 \text { if the company gets an opinion regarding the doubt on going concern, and } 0 \\
\text { otherwise. }\end{array}$ \\
Investment & $\begin{array}{l}\text { The ratio of total cash and cash equivalents, short-term investments, and long-term } \\
\text { investments divided by total assets } \\
\text { The ratio of total debt divided by total assets }\end{array}$ \\
Leverage (LEV) & $\begin{array}{l}\text { The ratio of total operational cash flows divided by total assets } \\
1 \text { if the company suffered a loss in the previous year, and } 0 \text { otherwise }\end{array}$ \\
\hline
\end{tabular}

Table 1 describes the variables used in the study, which are Management Overconfidence (OC), Audit Going Concern (GCO), Investment, Leverage (LEV), OCF, and Lag Loss. 
Table 2. Results Using Investment Dependent Variable

\begin{tabular}{|c|c|c|c|}
\hline $\begin{array}{l}\text { Dependent } \\
\text { Variable }\end{array}$ & Independent Variable & $\begin{array}{c}\text { Mean Square Error } \\
\text { (MSE) }\end{array}$ & $\begin{array}{c}\text { Mean Prediction Error } \\
\text { (MPE) }\end{array}$ \\
\hline Investment & $\mathrm{OC}, \mathrm{GCO}$ & 0 & 0 \\
\hline Investment & OC, LEV & 0 & 0 \\
\hline Investment & OC, LAG LOSS & $\mathrm{NaN}$ & $\mathrm{NaN}$ \\
\hline Investment & OC, LEV, LAG LOSS & Infinity & Infinity \\
\hline Investment & $\mathrm{OC}, \mathrm{OCF}$ & 0 & 0 \\
\hline Investment & OC, LAG LOSS & $\mathrm{NaN}$ & $\mathrm{NaN}$ \\
\hline Investment & $\begin{array}{l}\text { OC, LEV, LAG LOSS, } \\
\text { OCF }\end{array}$ & 0 & 0 \\
\hline Investment & GCO, LEV & 0 & 0 \\
\hline Investment & GCO, LAG LOSS & $\mathrm{NaN}$ & $\mathrm{NaN}$ \\
\hline Investment & GCO, LEV, LAG LOSS & Infinity & Infinity \\
\hline Investment & $\begin{array}{l}\text { OC, LEV, LAG LOSS, } \\
\text { OCF }\end{array}$ & 0 & 0 \\
\hline
\end{tabular}

Table 2 shows that GOC, OC, LEV, OCF, and Lag Loss affect Investments, both calculated simultaneously, unless Lag Loss is unpredictable with only one variable. (This means that last year's profit/loss cannot be a guideline for bankruptcy predictions. It needs another variable to make the forecast.).

Table 3. Results Using Dependent LEVERAGE Variable

\begin{tabular}{cccc}
\hline $\begin{array}{c}\text { Dependent } \\
\text { Variable }\end{array}$ & Independent Variable & $\begin{array}{c}\text { Mean Square } \\
\text { Error (MSE) }\end{array}$ & $\begin{array}{c}\text { Mean Prediction } \\
\text { Error (MPE) }\end{array}$ \\
\hline LEV & OC, GCO & 0 & 0 \\
LEV & OC, LEV & 0 & 0 \\
LEV & OC, LAG LOSS & NaN & NaN \\
LEV & OC, LEV, LAG LOSS & Infinity & Infinity \\
LEV & OC, OCF & 0 & 0 \\
LEV & OC, LAG LOSS & NaN & NaN \\
LEV & OC, LEV, LAG LOSS, OCF & 0 & 0 \\
LEV & GCO, LEV & 0 & 0 \\
LEV & GCO, LAG LOSS & NaN & NaN \\
LEV & GCO, LEV, LAG LOSS & Infinity & Infinity \\
LEV & OC, LEV, LAG LOSS, OCF & 0 & 0 \\
\hline
\end{tabular}

Table 3 shows that GOC, OC, LEV, OCF, and Lag Loss affect Leverage, both calculated simultaneously, unless Lag Loss is unpredictable if with only one variable. (This means that 
last year's profit/loss cannot be a guideline for bankruptcy predictions. It needs another variable to make the forecast.).

\section{Conclusion}

The credit volume of the financial industry has increased rapidly in recent years. At the same time, the non-performing loans (NPL) volume has also increased parallel with the global financial crisis. It has become increasingly important for credit institutions to find good consumers capable of fulfilling their financial obligations. To do that, financial institutions use credit scoring models as a decision support system to evaluate credit applications. Many credit scoring models have been developed for better credit approval processes. ANN and fuzzy logic (FL) have gained a lot of interest in the last two decades. ANN has learning ability, but it cannot be interpreted as the decision-making process stays in a black box. FL systems have interpretable linguistic rules, but they have no learning ability. Neuro-fuzzy (NF) systems use ANN and FL simultaneously and have the advantages of both. This study proposes a three-stage hybrid ANFIS credit scoring model based on statistical techniques and NF. To demonstrate the performance of the proposed model, audit results for corporations in Indonesia from 2014-2016 were evaluated. Our empirical results show that ANFIS can be used for analysis and forecasting of GOC, OC, OCF, and Lag Loss variables that affect Investment and Leverage, both compared to standalone analysis and forecasting simultaneously, unless Lag Loss is unpredictable if there is only one variable. This means that last year's profit/loss cannot be used as a guideline for the prediction of corporate bankruptcy, and other variables are required to make a prediction.

\section{Acknowledgments}

The authors would like to express sincere appreciation to the anonymous reviewers for their constructive and valuable suggestions, which were extremely helpful to guarantee the quality of this paper. The Vocational Program, Universitas Indonesia sponsored this study.

\section{References}

Adam, T. R., Fernando, C.S., \& Golubeva, E. (2015). Managerial overconfidence and corporate risk management. Journal of Banking and Finance, 60, 195-208. Retrieved from http://dx.doi.org/10.1016/j.jbankfin.2015.07.013

Adams, Z., \& Glück, T. (2015). Financialization in commodity markets: A passing trend or the new normal?. Journal of Banking and Finance, 60, 93-111. Retrieved from http://dx.doi.org/10.1016/j.jbankfin.2015.07.008

Boučková, M. (2015). Management accounting and agency theory. Procedia Economics and Finance, 25(15), 5-13. Retrieved from http://linkinghub.elsevier.com/retrieve/pii/S2212567115007078

Chou, C. H., Hsieh, S. C., \& Qiu, C. J. (2017). Hybrid Genetic Algorithm and Fuzzy Clustering for Bankruptcy Prediction. Applied Soft Computing Journal, 56, 298-316. Retrieved from http://dx.doi.org/10.1016/j.asoc.2017.03.014

Chung, D. Y., Hrazdil, K., \& Trottier, K. (2015). On the Efficiency of Intra-Industry Information Transfers: The Dilution of the Overreaction Anomaly. Journal of Banking and Finance, 60, 153-167. Retrieved from http://dx.doi.org/10.1016/j.jbankfin.2015.08.013

Foster, B. P., \& Shastri, T. (2016). Determinants of Going Concern Opinions and Audit Fees for Development Stage Enterprises. Advances in Accounting, 33, 68-84. Retrieved from http://dx.doi.org/10.1016/j.adiac.2016.05.001

Măciucă, G., Hlaciuc, E., \& Ursache, A. (2015). The Role of Prudence in Financial Reporting: IFRS versus Directive. Procedia Economics and Finance, 32(15), 738-744.

George-Silviu, C., \& Melinda-Timea, F. (2015). New Audit Reporting Challenges: Auditing the Going Concern Basis of Accounting, Procedia Economics and Finance, 32(15), 216-24.

Hill, M. S., Lopez, T. J., \& Reitenga, A. L. (2016). CEO Excess Compensation: The Impact of Firm Size and Managerial Power. Advances in Accounting, 33, 35-46. Retrieved from http://dx.doi.org/10.1016/j.adiac.2016.04.007

Ittonen, K., Tronnes, P. C., \& Wong, L. (2017). Substantial Doubt and the Entropy of Auditors' Going Concern Modifications. Journal of Contemporary Accounting \& Economics, 13(2), 134-147. Retrieved from http://dx.doi.org/10.1016/j.jcae.2017.05.005

Jha, A., \& Cox, J. (2015). Corporate Social Responsibility and Social Capital. Journal of Banking and Finance, 60, 252-270. Retrieved from http://dx.doi.org/10.1016/j.jbankfin.2015.08.003 
Kalelkar, R. (2016). Audit committee diligence around initial audit engagement. Advances in Accounting, 33, 59-67. Retrieved from http://dx.doi.org/10.1016/j.adiac.2016.04.009

Lai, J. H., Lin, W. C., \& Chen, L. Y. (2017). "The influence of CEO overconfidence on ownership choice in foreign market entry decisions." International Business Review, 26(4), 774-785.

Lian, Y. (2017). Financial distress and customer-supplier relationships. Journal of Corporate Finance, 43, 397-406. Retrieved from http://dx.doi.org/10.1016/j.jcorpfin.2017.02.006

Lin, Y. C., \& Yeh, C. H. (2014). "Grey relational analysis based artificial neural network for product design. In 2015 12th International Conference on Informatics in Control, Automation and Robotics (ICINCO), 1, 653-658. IEEE.

Packham, N. (2018). Optimal contracts under competition when uncertainty from adverse selection and moral hazard are present. Statistics and Probability Letters, 137, 99-104. Retrieved from https://doi.org/10.1016/j.spl.2018.01.014

Rodriguez-Fernandez, M. (2016). Social responsibility and financial performance: The role of good corporate governance. $B R Q$ Business Research Quarterly, 19(2), 137-51. Retrieved from http://dx.doi.org/10.1016/j.brq.2015.08.001

Sedmihradská, L. 2015. Budget transparency in Czech local government. Procedia Economics and Finance, 25, 598-606. Retrieved from http://dx.doi.org/10.1016/S2212-5671(15)00774-1

Dănescu, T., Prozan, M., \& Prozan, R. D. (2015). Perspectives regarding accounting -corporate governance- internal control. Procedia Economics and Finance, 32(15), 588-594.

Wan, Y., \& Si, Y. W. (2017). Adaptive neuro fuzzy inference system for chart pattern matching in financial time series. Applied Soft Computing Journal, 57, 1-18. Retrieved from http://dx.doi.org/10.1016/j.asoc.2017.03.023 